\title{
Studying the Utilization of Plastic Waste by Chemical Recycling Method
}

\author{
Adil Koç \\ Chemical Engineering Department, Engineering Faculty, Inonu University, Malatya, Turkey \\ Email: adil.koc@inonu.edu.tr
}

Received November 19, 2012; revised January 8, 2013; accepted January 18, 2013

Copyright (C) 2013 Adil Koç. This is an open access article distributed under the Creative Commons Attribution License, which permits unrestricted use, distribution, and reproduction in any medium, provided the original work is properly cited.

\begin{abstract}
The rapid increase in the use of plastic materials in the recent years led to the accumulation of excessive amounts of plastic waste. The so-called thermoplastics such as PE, PP, PS, PVC and PET as well as materials that are derived from these are the type of plastic that is most used and consequently creates most of the waste. In this study, the original and waste forms of $\mathrm{PE}$ and PP plastic types have been chosen for thermal and catalytic degradation. As process parameter, $410^{\circ} \mathrm{C}-450^{\circ} \mathrm{C}$ temperature interval and $600 \mathrm{~mL} / \mathrm{min}$ constant flow rate nitrogen gas have been chosen as the carrier gas and the reaction time was considered to be 90 minutes for all experiments. Liquid products collected in experiments were separated by means of fractioned distillation process. For purposes of determining product distribution, the fractions, which were separated by distillation, were diluted in an appropriate solution for analysis of GC/MS. In the study conducted, it has been observed that the liquid product distribution obtained mainly consists of a mixture of saturated and unsaturated (heptane, heptane, octane, nonane, dodecane, etc.) hydrocarbons.
\end{abstract}

Keywords: Waste Plastics; Chemical Recycling; Catalyst

\section{Introduction}

Nowadays plastic materials have become an indispensable part of social life and the fact that they generate excessive amounts of waste causes large economic losses. For purposes of recovering these plastic materials various pyrolysis techniques (thermal, catalytic, inert atmosphere, oxygen environment, under high pressure pyrolysis, etc.) have been developed. Due to its unique structure and properties (cheap, high resistance against impact, easy processing, etc.), polyethylene is used more commonly in comparison to other plastic types such as PP, PS, PET, $\mathrm{PVC}$ and consequently more waste is formed [1-5]. In a plastic degradation study, it has been reported that the reaction products consist of a hydrocarbon mixture such as water insoluble saturated and unsaturated petrochemical raw material and that the distribution of molecular weights of these products is determined. By applying thermo-gravimetric method and thermal degradation technique, oxygenated and non-oxygenated polymers were degraded in a reactor consisting of different sections [6, 7]. In these studies some kinetic parameters were determined and it has been claimed that the liquid products obtained especially by degeneration of oxygenated poly- mers were alcohol, alkene, ether (ethoxymethane, ethoxy ethane, methoxy methane, etc.), aldehydes, $\mathrm{CO}$ and $\mathrm{CO}_{2}$. In some studies it has been shown that when waste plastic mixture pyrolysis is implemented in hydrogen atmosphere and gas oil by using synthetic zeolite (Co-Ac, DHC) catalysts, a high rate of liquid product was obtained $[6,8]$. Due to the fact that products similar to fuel and petrochemical raw material quality can be generated through thermal and catalytic pyrolysis of plastic waste, these are considered to be important recovery methods. In the study of HDPE plastics pyrolysis, one group of researchers has been reported to have obtained liquid product in C5-C28 carbon range consisting of high rate of paraffin and aromatic component mixture [9-13]. PE plastics were pyrolyzed in different reactors for purposes of analyzing pyrolytic medium and it has been reported that residence time and reaction temperature are parameters that are effective on degradation mechanism [14,15]. Some original and waste plastic types such as PE, PP, PS were pyrolyzed and it has been reported that alkene/ paraffin ratio was an important parameter in pyrolysis of plastic mixture [16,17]. Additionally, in the same study, it has been claimed that the reaction rate constant in- 
creased significantly by increasing the amount of PS in the mixture. In Japan, a plastic waste recycling plant was opened in the year of 1997, and it has been indicated that plastic waste could be used in blast furnace applications, coke oven applications and gasification processes [18]. In plastic pyrolysis studies, conducted in continuous tubular flow reactor, it was reported that a liquid mixture of wide carbon number such as gasoline, refinery raw material and similar liquid chemicals was obtained [18]. In some studies it has been reported that new products were formed when the long chain making up the polymeric substance is broken in pyrolysis of a polymer [19-21]. Furthermore, it has been indicated that the pyrolysis mechanism could be brought to light as such and asserted that kinetic parameters could be determined with the help of this mechanism. Due to the fact that plastic material could stay a very long time without degradation in the environment, great effort has been expanded for the production of biodegradable polymer materials especially in recent years [22-26]. In a study involving the thermal and $\mathrm{BaCO}_{3}$ catalytic pyrolysis of HDPE material, it has been reported that the liquid products obtained at $450^{\circ} \mathrm{C}$ temperature and 0.1 catalyst/plastic ratio display the properties similar to gasoline, kerosene and fuel oil [27,28]. In the subject matter study, catalytic and thermal degradation of HDPE and PP were studied and the effects of some factors such as catalysts and temperature on degradation products were analyzed. In pyrolysis studies, the yield of the liquid product obtained was determined and the characterization of this liquid product was elucidated by $\mathrm{GC} / \mathrm{MS}$ analysis.

\section{Experimental}

\subsection{Experimental Equipment and Raw Materials}

In this study HDPE and PP samples, which are in original (F12, which named by producer) and waste form (milk bottles, shampoo bottles, detergent bottles, etc.) were degraded under atmospheric conditions in a cylin- drical horizontal furnace reactor. The furnace operates on the basis of a temperature controlled system containing a heating zone that is $50 \mathrm{~mm}$ in diameter and $450 \mathrm{~mm}$ long. A glass reactor of $40 \mathrm{~mm}$ diameter with $350 \mathrm{~mL}$ operating capacity was placed in the furnace. The reaction temperature of the glass reactor is controllable (Figure 1).

The detailed schematic presentation of reactor has shown in Figure 2. The reactor has three parts, where the reaction area and inner and outer contact of reactor. The feed into reactor was batch operation than established the center of oven which its temperature was settled previously.

For purposes of measuring the temperature of the furnace and the reaction environment, thermocouples were placed at different places, and with the help of these thermocouples the temperature profiles of the furnace and reaction zone were determined. In experimental studies, nitrogen gas was selected as the carrier gas and in order to establish an inert environment and it was maintained constantly at $600 \mathrm{~mL} / \mathrm{min}$ flowrate. The gas-vapor mixture emitted by the reactor was passed through a precooler with air cooling and the liquefied products were collected in containers that were placed in salt-ice bath (approximately $-16^{\circ} \mathrm{C}$ ). The same system was also used for catalytic degradation studies in addition to thermal degradation. By using $\mathrm{SiO}_{2}$ support material, Co and Mo catalysts were prepared in different percent ratios (by weight) to be used in catalytic degradation experiments of HDPE and PP plastics. The effects of environmental conditions on the collected liquid product yield and characterization for catalytic and thermal degradation were studied.

\subsection{Catalyst Preparation}

Co and Mo cracking catalysts were prepared with the purpose of using them in experimental studies. A specific percentage ratio of each catalyst (by weight) was taken in the amount calculated according to the salts with high solubility in water for this purpose, and after dissolving

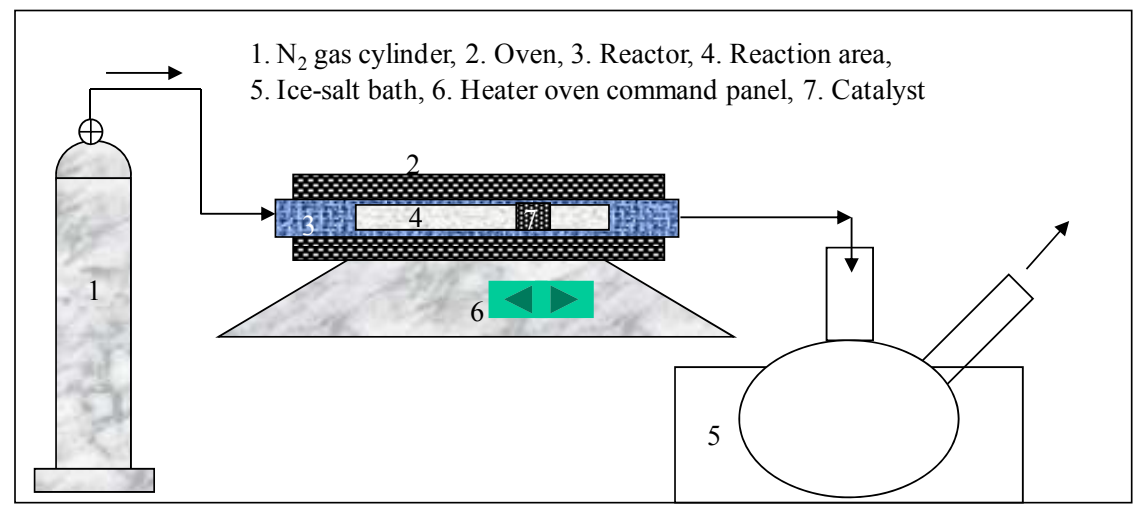

Figure 1. Experimental set-up. 


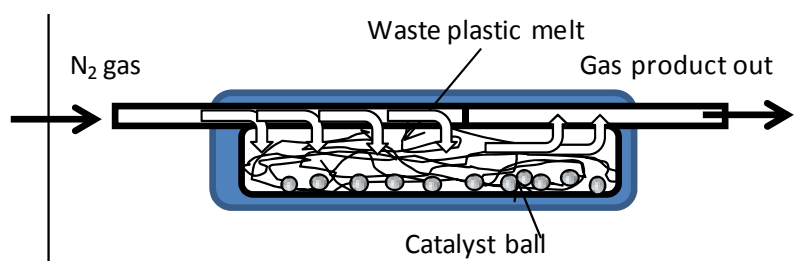

Figure 2. Detailed reactor scheme.

in water it was adsorbed onto the support material. To prepare Cobalt $(\mathrm{Co})$ catalyst cobalt-II-nitrate hexa-hydrate salt $\left[\mathrm{Co}\left(\mathrm{NO}_{3}\right)_{2} 6 \mathrm{H}_{2} \mathrm{O}\right]$, and to prepare molybdenum (Mo) catalyst ammonium molybdate tetra hydrate

$\left[\left(\mathrm{NH}_{4}\right)_{6} \mathrm{Mo}_{7} \mathrm{O}_{24} \cdot 4 \mathrm{H}_{2} \mathrm{O}\right]$ sale was selected. To prepare catalysts of different percentage ratios $(1 \%, 5 \% 10 \%$, by weight) the salts indicated were placed in a beaker in the ratios calculated. Later on the salt was dissolved in distilled water and finally added to $\mathrm{SiO}_{2}$ salt solution that was used as support material and dried in oven at $110^{\circ} \mathrm{C}$. After a waiting period of approximately 24 - 36 hours, the catalyst was placed in $110^{\circ} \mathrm{C}$ oven for purposes of removing its water and its water was evaporated. Finally the catalyst was subjected to calcination process to achieve its form for use.

\subsection{Calcination of Catalyst}

After the removal of its water and being dried, raw catalyst was let stand in a muffle furnace at different temperatures and for different time periods. To serve this purpose the standing periods indicated in the following table was applied (Table 1). At the end of the standing period the catalyst, which was removed from the hot oven, was cooled in a desiccator and stored in glass jars for experimental studies.

The SEM-EDX compound content of Co-Mo catalyst was presented in Table 2. We can see in this table that this catalyst is formed of $\mathrm{Co}$, Mo and $\mathrm{SiO}_{2}$, which is a support material. And the detailed estimation of form of this catalyst is shown in Figure 3 too.

\section{Result and Discussion}

The effects of different environmental conditions on the liquid product were analyzed in experimental studies, and their iodine numbers were attempted to be determined with the purpose of determining how unsaturated liquid products were. The liquid products collected in the coolers located at the outlet of the reactor were subjected to distillation process under atmospheric conditions in order to be able to determine the boiling point distribution. Later, the same liquid fractions were prepared for GC/MS analysis by being dissolved in a suitable solvent and the characterization of liquid products were determined by GC/MS analysis. In thermal and catalytic degradation experiments of PP and HDPE plastics, nitrogen
Table 1. Catalyst calcinations and temperature periods.

\begin{tabular}{ccccc}
\hline Catalysts & \multicolumn{4}{c}{ Co or Mo } \\
\hline Temperatures, ${ }^{\circ} \mathrm{C}$ & 350 & 450 & 550 & 600 \\
Waited time, min. & 60 & 90 & 120 & 60 \\
\hline
\end{tabular}

Table 2. The SEM-EDX compound content of Co-Mo catalyst.

\begin{tabular}{|c|c|c|c|c|c|c|}
\hline \multicolumn{3}{|c|}{$\begin{array}{c}\text { Date:30/03/2012 } \\
11: 05: 48\end{array}$} & \multicolumn{2}{|c|}{ HV: $20.0 \mathrm{kV}$} & \multicolumn{2}{|c|}{ Puls th.: $6.16 \mathrm{kcps}$} \\
\hline El & AN & Series & $\begin{array}{l}\text { unn. C } \\
{[\mathrm{wt} \%]}\end{array}$ & $\begin{array}{c}\text { norm. C } \\
{[\mathrm{wt} \%]}\end{array}$ & $\begin{array}{c}\text { Atom. C } \\
{[a t \%]}\end{array}$ & Error [\%] \\
\hline $\mathrm{Si}$ & 14 & K-series & 10.50 & 15.03 & 37.46 & 0.5 \\
\hline Co & 27 & $\mathrm{~K}$-series & 0.86 & 1.23 & 1.47 & 0.1 \\
\hline \multirow[t]{2}{*}{ Mo } & 42 & L-series & 58.49 & 83.73 & 61.07 & 2.1 \\
\hline & & Total: & 69.85 & 100.00 & 100.00 & \\
\hline
\end{tabular}

gas was selected as the carrier gas and it was maintained constant at $600 \mathrm{~mL} / \mathrm{min}$ while the experiment temperature interval was set to $410^{\circ} \mathrm{C}-450^{\circ} \mathrm{C}$.

At $425^{\circ} \mathrm{C}$ temperature, the effects of catalyst/plastic ratio on PP-HDPE degradation products were examined and the change shown in Figure 4 was obtained. According to Figure 4, the liquid product yield displays an increase with the increase in catalyst/plastic ratio (increases approximately from $60 \%$ to $82 \%$ (by weight)). In contract to this there were no significant changes in the number of iodine and residue amounts (what is left over in the reactor after degradation) and while the iodine number remained approximately around $53 \mathrm{~g} / 100 \mathrm{~g}$ of liquid, the residue amount was $4 \%$. The fact that the iodine number did not change significantly means that the ratio of unsaturated liquid products under these environmental conditions did not change much. (The iodine number provides information as to the ratio of unsaturated components available in the environment and this has been determined analytically as per ASTM D4607-94 standard). From the same figure, we can see that the highest liquid yield was obtained when the catalyst/plastic ratio is 0.2 . This means that in this plastic degradation study, if for each 5 grams of plastic 1 gram of catalyst is used, the highest liquid yield would be obtained. And this value has been determined to be $82 \%$ (by weight). This demonstrated that using a catalyst would yield more of the liquid product in comparison to the conditions where a catalyst is not used.

Changes in the liquid product yield and iodine number against catalyst/plastic ratio are provided in Figure 5 for catalytic degradation of HDPE at $450^{\circ} \mathrm{C}$ temperature. According to Figure 5, the highest liquid product and lowest residue amounts were obtained at 0.1 catalyst/ plastic ratio. Furthermore, we can see from Figure 5 that maximum residue and liquid amounts are approximately $12 \%$ and $77 \%$ (by weight) respectively at $450^{\circ} \mathrm{C}$ tem- 

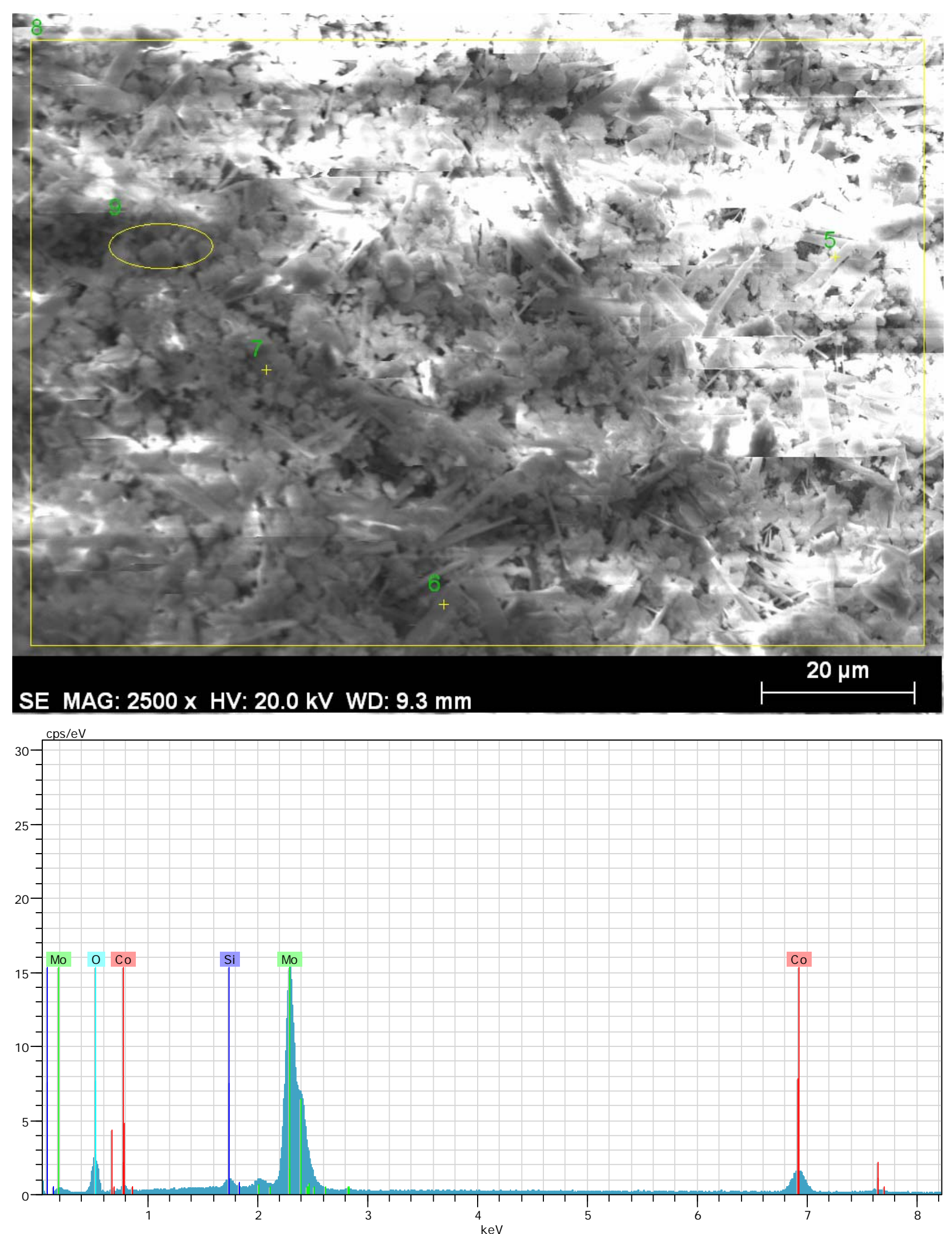

Figure 3. The SEM-EDX presentation of Co-Mo catalyst. 


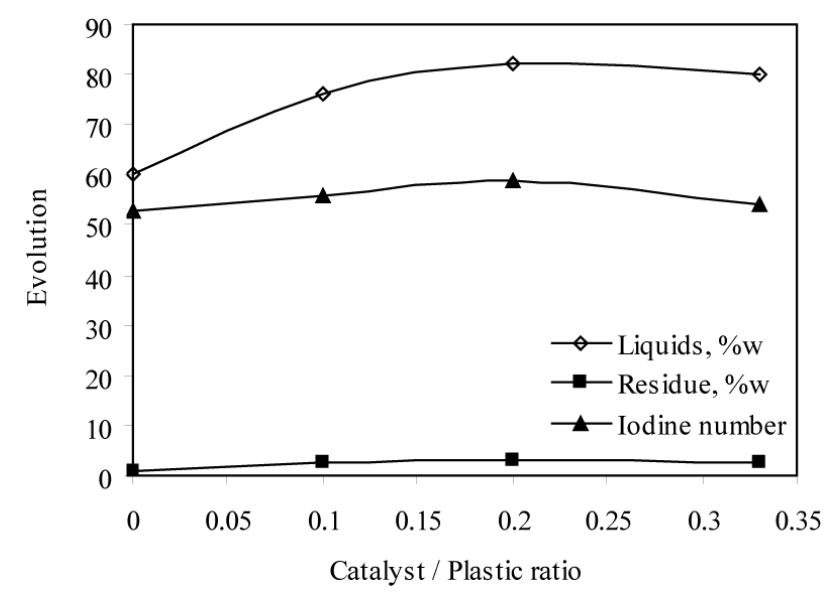

Figure 4. The variation of liquid products, residue and iodine numbers of PP-HDPE mixture degradation with catalyst/plastic ratio at $425^{\circ} \mathrm{C}$ temperature.

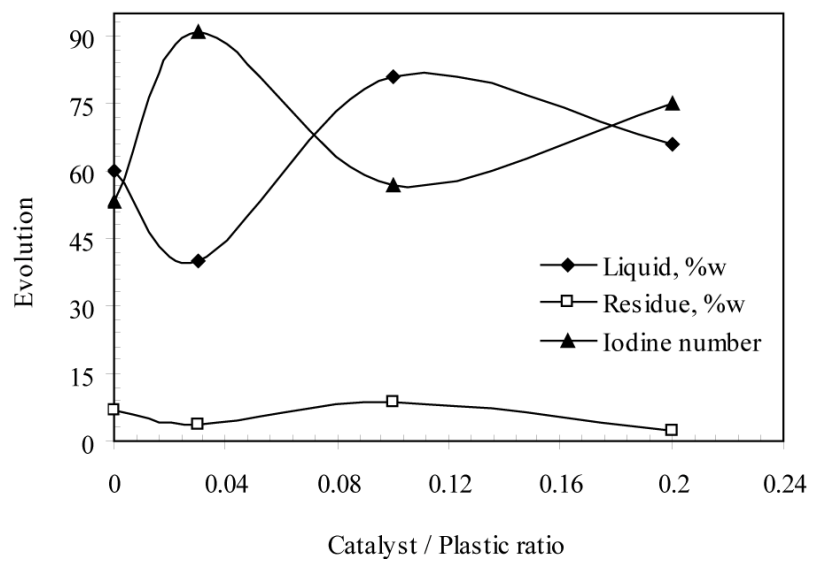

Figure 5. The variation of degradation products of LDPE and iodine numbers with catalyst/plastic ratio at $450^{\circ} \mathrm{C}$ temperature.

perature and 0.1 catalyst/plastic ratio. However, we can say that the highest iodine number was determined for 0.03 catalyst/plastic ratio at the same temperature, and under these conditions, more unsaturated liquid product was obtained in comparison to other catalyst/plastic ratios. Accordingly, if it is desired to obtain higher amounts of unsaturated liquid product, the use of a catalyst/plastic ratio of 0.03 would be required.

The change in the reaction products and iodine number with temperature in degradation of HDPE at 1/10 catalyst/plastic ratio are provided in Figure 6. According to Figure 6, the liquid product yield increased with the temperature in the degradation of HDPE and the highest liquid yield of approximately $78 \%$ was obtained at $440^{\circ} \mathrm{C}$ temperature. However, it was also observed that the amount of residue decreases with the increases in temperature and the highest residue amount is obtained at the lowest study temperature of $410^{\circ} \mathrm{C}$. This means that the HDPE degradation study is not deliberate at low tem-

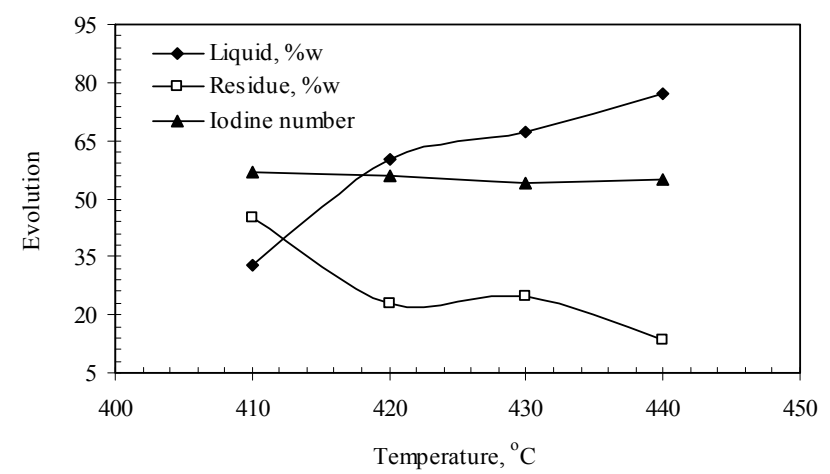

Figure 6. The variation of amount of liquid products, residue and iodine numbers of degradation of LDPE with temperature at 1/10 catalyst/plastic ratio.

peratures even if a catalyst is used. It can be observed that the iodine number does not change much with the temperature and remains at approximately $56 \mathrm{~g} / 100 \mathrm{~g}$ of liquid at all temperatures. For this reason the saturation of liquid products did not show much change as the catalyst/plastic ratio remained constant. However, it must be noted that the saturation of liquid products as shown in Figure 5 above was determined to change on the basis of the catalyst/plastic ratio.

It has been determined that the boiling point distribution of the distilled product of liquid products obtained in the catalytic degradation of HDPE at $450^{\circ} \mathrm{C}$ temperature, changes with the changes in the catalyst/plastic ratio as shown in Table 3. It can be said that, the boiling temperature range at maximum catalyst/plastic ratio of $3 / 30$ is $130^{\circ} \mathrm{C}-250^{\circ} \mathrm{C}$, while the boiling temperature range is revealed to be $80^{\circ} \mathrm{C}-250^{\circ} \mathrm{C}$ for the liquid products at catalyst/plastic ratio of $1 / 30$. Therefore, the boiling temperature of liquid products obtained at higher catalyst/plastic ratios is higher. Moreover, the liquid products in possession of lower boiling temperatures at lower catalyst/plastic ratios seem to be obtained in a wider range of boiling point temperature.

The temperature distribution during fractioned distillation of liquid products obtained in the study of PP Degradation at different temperatures $\left(425^{\circ} \mathrm{C}\right.$ and $\left.450^{\circ} \mathrm{C}\right)$ is shown in Figure 7. According to Figure 7, while the approximate boiling point of the product when the condensation starts during the distillation of the liquid product obtained at $425^{\circ} \mathrm{C}$ is $65^{\circ} \mathrm{C}$, this temperature for the liquid product obtained at the temperature of $450^{\circ} \mathrm{C}$ is $77^{\circ} \mathrm{C}$. At the beginning of distillation, the distillate temperature obtained showed a rapid increase and in approximately 10 minutes reached $175^{\circ} \mathrm{C}$ levels. After this temperature level, a significant change did not occur during distillation in the distillation temperature of the liquid product obtained at $425^{\circ} \mathrm{C}$. However in the distillation of the liquid product, which was obtained at $450^{\circ} \mathrm{C}$, an increase has been observed after the $25^{\text {th }}$ minute and the 
distillate temperature increased to $215^{\circ} \mathrm{C}$ by the end of the distillation process.

Distillation process was applied to determine the distribution of the liquid product obtained by catalytic degradation of $\mathrm{PP}$ at $425^{\circ} \mathrm{C}$ temperature. After distillation samples were obtained from these fractions and they were dissolved in a suitable solvent (such as $\mathrm{CCI}_{4}$ ) and subjected to GC/MS analysis. The chromatogram displayed a change as shown in Figure $\mathbf{7}$ and the results are summarized in Table 4 . When the Table 4 and chromatogram (Figure 8) are evaluated together, it can be seen that the liquid product obtained includes a high rate of

Table 3. The effect of catalyst/plastic ratio on distillation range of $\mathrm{HDPE}$ degradation at $450^{\circ} \mathrm{C}$ temperature.

\begin{tabular}{ccc}
\hline Catalyst/Plastic ratio & Distillation part, $\% \mathrm{w}$ & BP range, ${ }^{\circ} \mathrm{C}$ \\
\hline $3 / 30$ & 39 & $130-255$ \\
$1 / 30$ & 33 & $80-250$ \\
\hline
\end{tabular}

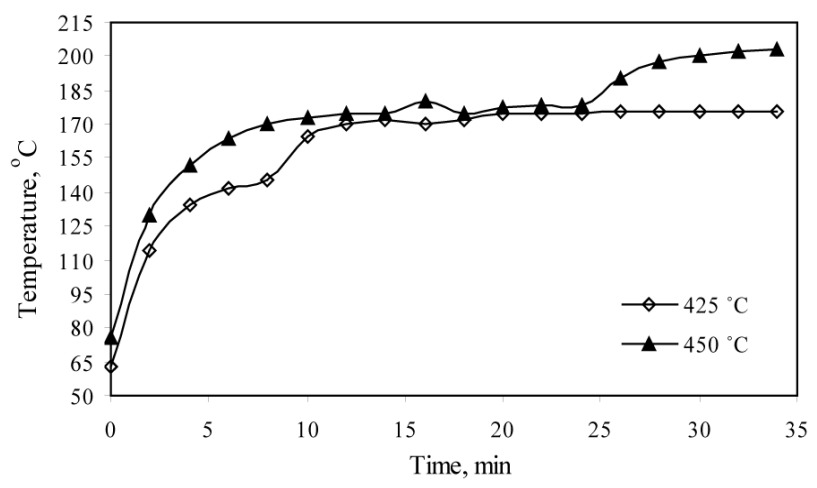

Figure 7. The variation of distillation temperature of liquid products of PP degradation at different temperatures. saturated (paraffin) structure components and that additionally there are unsaturated (olefin) hydrocarbon mixtures with aromatic structure.

It is possible to comment on the carbon atom number of the degradation product of PP plastics degraded at $425^{\circ} \mathrm{C}$ by evaluating Table 5 and Figure 9 together. According to Figure 9, the carbon atom number distribution is between $\mathrm{C} 5-\mathrm{C} 18$ range, while $\mathrm{C} 8-\mathrm{C} 12$ carbon numbered products are higher in concentration. From Table 5

Table 4. The product distribution of catalytic degradation of HDPE at $425^{\circ} \mathrm{C}$ temperature conditions.

\begin{tabular}{ccc}
\hline Peak number & Retention time & Compound name \\
\hline 1 & 4.35 & 1-Heptene \\
2 & 4.51 & 2,4-Dimethyl, Heptane \\
3 & 5.22 & 1-Octene \\
4 & 4.21 & Nonane \\
5 & 5.25 & Cyclopropane, 1-methl, 2-penthyl \\
6 & 5.11 & n-Decane \\
7 & 4.25 & n-Undecane \\
8 & 4.69 & Cyclopropane, \\
& & 1-penthyl-2-prophyl-5-undecene \\
9 & 4.89 & o-Xylene \\
10 & 5.92 & 1-Dodecane \\
11 & 5.12 & 1-Cyclododecane \\
12 & 5.33 & Benzene, 1-3-5 Trymethyl \\
13 & 5.92 & Tetradecane \\
14 & 6.32 & Tetradecene \\
15 & 5.24 & Pentadecane \\
16 & 4.57 & Hexadecane \\
17 & 5.85 & Heptadecane \\
18 & 6.32 & Octadecene \\
19 & 6.56 &
\end{tabular}

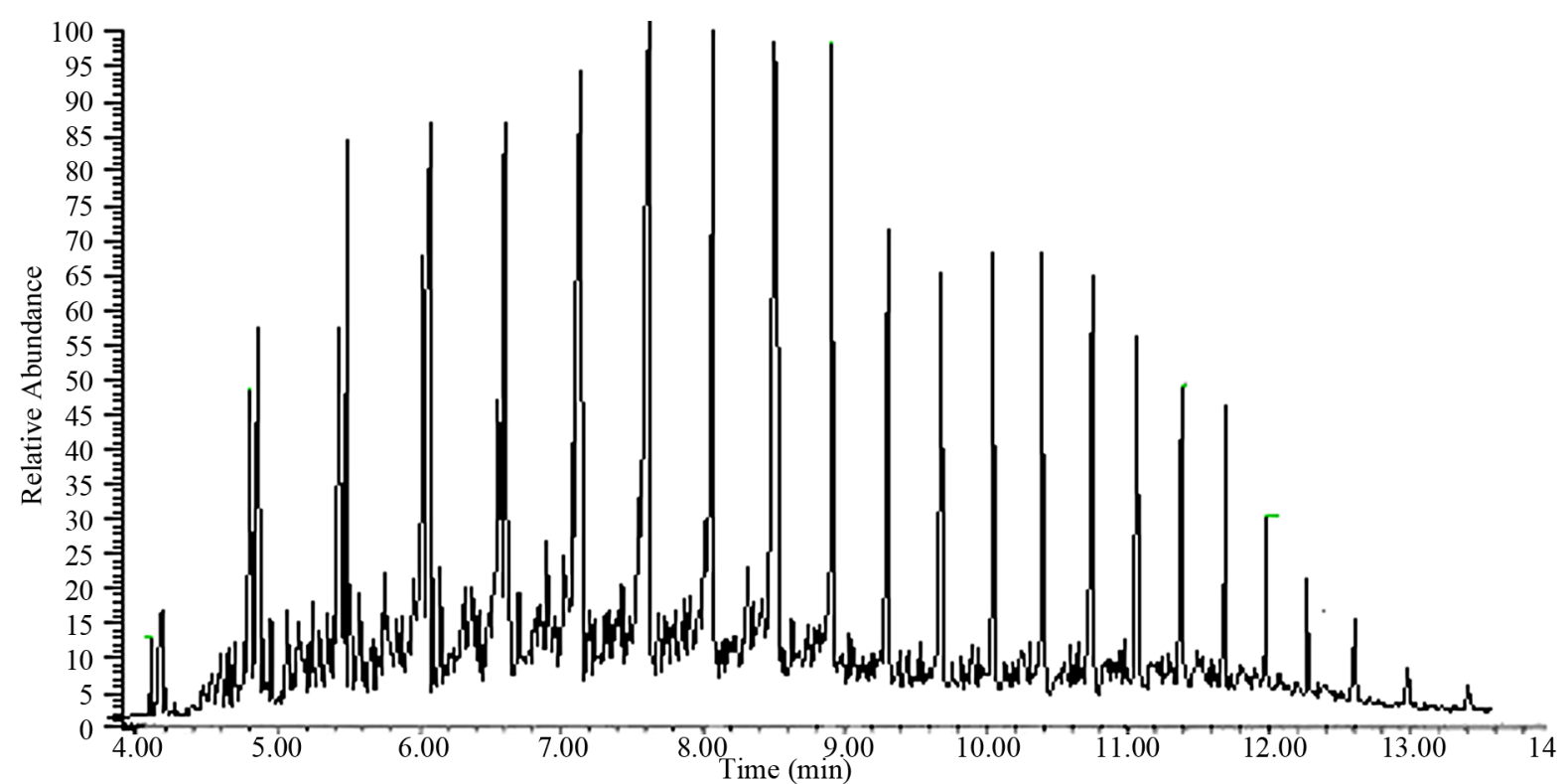

Figure 8. The GC/MS chromatogram of catalytic degradation products of $\mathrm{PP}$ at $425^{\circ} \mathrm{C}$ temperature. 
Table 5. The product group distribution of catalytic degradation of HDPE at $425^{\circ} \mathrm{C}$ temperature by GC/MS analysis.

\begin{tabular}{cc}
\hline Compound group & Peak area (in percentage) \\
\hline Olefins & 26.15 \\
Paraffins & 46.26 \\
Aromatics & 10.81 \\
Cyclic & 15.86 \\
Unknown & 0.92 \\
Total & 100.00 \\
\hline
\end{tabular}

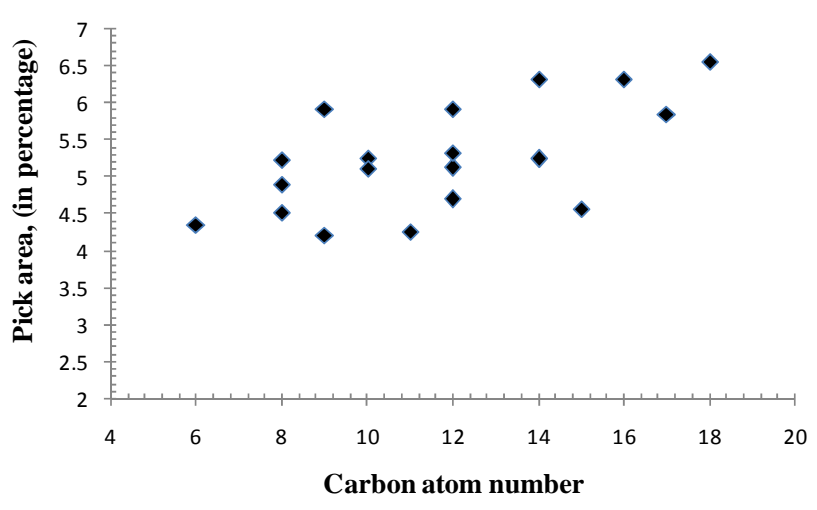

Figure 9. The variation of carbon atom numbers of catalytic degradation of $\mathrm{PP}$ at $425^{\circ} \mathrm{C}$ temperature.

it can be seen that there are small amounts of aromatic components $(10.81 \%)$ in the degradation products obtained at $425^{\circ} \mathrm{C}$, while products of paraffin quality are available at highest amounts (46.26\%).

\section{Conclusion}

The catalytic degradation of HDPE and PP shows us that in different catalyst/plastic ratios the amount and structure of liquid products are different. So the iodine number is an interesting parameter for unsaturated compounds determination. In this study, the unsaturated products are important part of the degradation products. In our later studies, the evolution of unsaturated product which they obtained in thermal or catalytic degradation processes will be investigated.

\section{Acknowledgements}

This work had been supported by UNIBAP 2011/45 Researche Project code.

\section{REFERENCES}

[1] J. G. Gao, M. S. Yu and Z. T. Lia, "Non-Isothermal Crystallization Kinetics and Melting Behavior of Bimodal Medium Density Polyethylene/Low Density Polyethylene Blends," European Polymer Journal, Vol. 40, No. 7, 2004, pp. 1533-1539.

[2] P. Krzysztof and F. Kinga, "Non-Oxidative Thermal Deg- radation of Poly (Ethylene Oxide): Kinetic and Thermo Analytical Study," Journal of Analytical and Applied Pyrolysis, Vol. 73, No. 1, 2005, pp. 131-138.

http://dx.doi.org/10.1016/j.jaap.2005.01.003

[3] M. Takao, K. Tatsuhiko, M. Toshihiro, S. R. Mukai, H. Kenji and S. I. Yoshida, "Chemical Recycling of Mixture of Waste Plastics Using a New Reactor System with Stirred Heat Medium Particles in Steam Atmosphere," Chemical Engineering Journal, Vol. 82, No. 1-3, 2001, pp. 173-181.

[4] A. András, N. Miskolczi and L. Bartha, "Petrochemical Feedstock by Thermal Cracking of Plastic Waste", Journal of Analytical and Applied Pyrolysis, Vol. 79, No. 1-2, 2007, pp. 409-414.

http://dx.doi.org/10.1016/j.jaap.2006.12.031

[5] A. S. Aamer, H. Fariha, H. Abdul and A. Safia, "Biological Degradation of Plastics: A Comprehensive Review," Biotechnology Advances, Vol. 26, No. 3, 2008, pp. 246265. http://dx.doi.org/10.1016/j.biotechadv.2007.12.005

[6] B. Robert, Jr. James, et al., "Process for the Conversion of Plastic to Produce a Synthetic Crude Oil," US Patent No. 6060631, 2000.

[7] K. Adil and A. Y. Bilgesu, "Catalytic and Thermal Oxidative Pyrolysis of LDPE in a Continuous Reactor System," Journal of Analytical and Applied Pyrolysis, Vol. 78, No. 1, 2007, pp. 7-13.

http://dx.doi.org/10.1016/j.jaap.2006.03.008

[8] A. Marcilla, A. Gómez-Siurana, A. O. Odjo, R. Navarro and D. Berenguer, "Characterization of Vacuum Gas Oilelow Density Polyethylene Blends by Thermogravimetric analysis," Polymer Degradation and Stability, Vol. 93, No. 3, 2008, pp. 723-730. http://dx.doi.org/10.1016/j.polymdegradstab.2007.12.010

[9] N. Miskolczi and L. Bartha, "Investigation of Hydrocarbon Fractions form Waste Plastic Recycling by FTIR, GC, EDXRFS and SEC Techniques," Journal of Biochemical and Biophysical Methods, Vol. 70, No. 6, 2008, pp. 12471253. http://dx.doi.org/10.1016/j.jbbm.2007.05.005

[10] N. K. Ciliz, E. Ekinci and C. E.Snape, "Pyrolysis of Virgin and Waste Polypropylene and Its Mixtures with Waste Polyethylene and Polystyrene," Waste Management, Vol. 24, No. 2, 2004, pp. 173-181. http://dx.doi.org/10.1016/j.wasman.2003.06.002

[11] A. Okuwaki, "Feedstock Recycling of Plastics in Japan," Polymer Degradation and Stability, Vol. 85, No. 3, 2004, pp. 981-988. http://dx.doi.org/10.1016/j.polymdegradstab.2004.01.023

[12] N. Miskolczia, L. Barthaa, G. Deáka, B. Jóverb and D. Kallóc, "Thermal and Thermo-Catalytic Degradation of High-Density Polyethylene Waste," Journal of Analytical and Applied Pyrolysis, Vol. 72, No. 2, 2004, pp. 235-242. http://dx.doi.org/10.1016/j.jaap.2004.07.002

[13] M. Wallis and S. K. Bhatia, "Kinetic Study of the Thermal Degradation of High Density Polyethylene," Polymer Degradation and Stability, Vol. 91, No. 7, 2006, pp. 14761483.

http://dx.doi.org/10.1016/j.polymdegradstab.2005.10.003

[14] U. Suat, K. Selhan, K. Tamer and Y. Jale, "Conversion of Polymers to Fuels in a Refinery Stream," Polymer Deg- 
radation and Stability, Vol. 75, No. 1, 2002, pp. 161-171. http://dx.doi.org/10.1016/S0141-3910(01)00215-4

[15] A. E. S. Greena and S. M. Sadramelib, "Analytical Representations of Experimental Polyethylene Pyrolysis Yields," Journal of Analytical and Applied Pyrolysis, Vol. 72, No. 2, 2004, pp. 329-335. http://dx.doi.org/10.1016/j.jaap.2004.07.006

[16] Y.-H. Seo, K.-H. Lee and D.-H. Shin, "Investigation of Catalytic Degradation of Highdensity Polyethylene by Hydrocarbon Group Type Analysis," Journal of Analytical and Applied Pyrolysis, Vol. 70, No. 2, 2003, pp. 383-398.

[17] J. Walendziewski, "Continuous Flow Cracking of Waste Plastics," Fuel Processing Technology, Vol. 86, No. 1213, 2005, pp. 1265-1278. http://dx.doi.org/10.1016/j.fuproc.2004.12.004

[18] M. L. Mastellone, F. Perugini, M. Ponte and U. Arena, "Fluidized Bed Pyrolysis of a Recycled Polyethylene," Polymer Degradation and Stability, Vol. 76, No. 3, 2002, pp. 479-487.

http://dx.doi.org/10.1016/S0141-3910(02)00052-6

[19] A. Marcilla, J. C. García-Quesada, S. Sánchez, and R. Ruiz, "Study of the Catalytic Pyrolysis Behaviour of Polyethylene-Polypropylene Mixtures," Journal of Analytical and Applied Pyrolysis, Vol. 74. No. 1-2, 2005, pp. 387-392. http://dx.doi.org/10.1016/j.jaap.2004.10.005

[20] J. Nishino, M. Itoh, H. Fujiyoshi and Y. Uemichi, "Catalytic Degradation of Plastic Waste into Petrochemicals Using Ga-ZSM-5," Fuel, Vol. 87, No. 17-18, 2008, pp. 3681-3686. http://dx.doi.org/10.1016/j.fuel.2008.06.022

[21] D. Na, Z. Yu-Feng and W. Yan, "Thermogravimetric Analysis and Kinetic Study on Pyrolysis of Representative Medical Waste Composition," Waste Management, Vol. 28, No. 9, 2008, pp. 1572-1580 http://dx.doi.org/10.1016/j.wasman.2007.05.024

[22] U. Hujuri, A. K. Ghoshal and S. Gumma, "Modeling Pyrolysis Kinetics of Plastic Mixtures," Polymer Degra- dation and Stability, Vol. 93, No. 10, 2008, pp. 1832$-1837$.

http://dx.doi.org/10.1016/i.polymdegradstab.2008.07.006

[23] B. Singh and N. Sharma, "Mechanistic Implications of Plastic Degradation," Polymer Degradation and Stability, Vol. 93, No. 3, 2008, pp. 561-584.

http://dx.doi.org/10.1016/j.polymdegradstab.2007.11.008

[24] A. K. Panda, R. K. Singh and D. K. Mishra, "Thermolysis of Waste Plastics to Liquid Fuel a Suitable Method for Plastic Waste Management and Manufacture of Value Added Products-A world Prospective," Renewable and Sustainable Energy Reviews, Vol. 14, No. 1, 2010, pp. 233-248. http://dx.doi.org/10.1016/j.rser.2009.07.005

[25] Y.-H. Lin, M.-H. Yang, T.-T. Wei, C.-T. Hsu, K.-J. Wu and S.-L. Lee, "Acid-Catalyzed Conversion of Chlorinated Plastic Waste into Valuable Hydrocarbons over PostUse Commercial FCC Catalysts," Journal of Analytical and Applied Pyrolysis, Vol. 87, No. 1, 2010, pp. 154-162. http://dx.doi.org/10.1016/j.jaap.2009.11.006

[26] N. Miskolczi, L. Bartha, G. Deáka and B. Jóverb, “Thermal Degradation of Municipal Plastic Waste for Production of Fuel-Like Hydrocarbons," Polymer Degradation and Stability, Vol. 86, No. 2, 2004, pp. 357-366. http://dx.doi.org/10.1016/j.polymdegradstab.2004.04.025

[27] M. Rasul Jan, J. Shah and H. Gulab, "Catalytic Degradation of Waste HDPE into Fuel Products Using $\mathrm{BaCO}_{3}$ as a Catalyst," Fuel Processing Technology, Vol. 91, No. 11, 2010, pp. 1428-1437. http://dx.doi.org/10.1016/j.fuproc.2010.05.017

[28] M. N. Almustapha and J. M. Andresen, "Catalytic Conversion of High Density Polyethylene (HDPE) Polymer as a Means of Recovering Valuable Energy Content from the Plastic Wastes," 2011 International Conference on Petroleum and Sustainable Development IPCBEE, Vol. 26, IACSIT Press, Singapore, 2011. 